\title{
Freeze-Drying of Wine Yeasts and Oenococcus oeni and Selection of the Inoculation Conditions after Storage
}

\section{Ale CE, Otero MC and Pasteris SE*}

Instituto Superior de Investigaciones Biológicas (INSIBIO), CONICET-UNT, and Instituto de Biología "Dr. Francisco D. Barbieri", Facultad de Bioquímica, Química y Farmacia, UNT, San Miguel de Tucumán, Argentina.

\begin{abstract}
Modern winemaking industry has new challenges focused on the application of preserved starter's microbial cultures for the optimization of the fermentation process that ensuring flavor characteristics and the reproducibility of the final products obtained. Thus, the aim of the present work was to select the inoculation conditions for preselected Saccharomyces cerevisiae $\mathrm{mc}_{2}(\mathrm{SC})$, Kloeckera apiculata $\mathrm{mF}(\mathrm{KA})$ and Oenococcus oeni $\mathrm{X}_{2} \mathrm{~L}(\mathrm{OO})$ after freeze-drying and storage in both pure and mixed cultures. The strains were grown in $17 \%$ Natural Grape Juice (NGJ) and then lyophilized in $10 \%$ individual sugars (glucose, fructose, sucrose, maltose and trehalose), $2.4 \%$ sodium glutamate, $4 \%$ yeast extract and NGJ by using different culture combinations: 1)- pure cultures (KA1, SC1, OO1), 2)- mixed yeast cultures (KA2, SC2), 3)- mixed microbial cultures (KA3, SC3, OO3). After lyophilization, the strains were stored for 12 months at 4 and $25^{\circ} \mathrm{C}$. Viability post-lyophilization was culture/lyoprotectant-dependent while survival to storage depended on time and temperature being $O$. oeni the more resistant strain to the all process, then K. apiculata and S. cerevisiae, respectively. Freeze-drying of mixed KA-SC in $10 \%$ fructose and $\mathrm{OO}$ in $17 \%$ NGJ up to 6 months of storage at $4^{\circ} \mathrm{C}$ were the best conditions for the maintenance of the fermentative properties of the strains and for glycerol production. The inoculation of grape musts with KA-SC and OO lyophilized individually with low-cost lyoprotectants would ensure the proper development of the fermentation processes and glycerol synthesis, thus increasing the organoleptic characteristics of wines by a non-Saccharomyces strain. Therefore, the starter culture should include K. apiculata, S. cerevisiae and O. oeni strains.
\end{abstract}

Keywords: Freeze-drying; Wine microorganisms; Lyoprotectants; Fermentative properties; Glycerol synthesis

\section{Introduction}

During the last 150 years, the scientific basis of the winemaking process has changed gradually as a result of numerous empirical procedures [1]. Nowadays, there are new focal points in the wine industry, including the genetic modification of both the wine microorganisms and the grape cultivar. Although in 1890 the novel concept of inoculating musts with yeast cultures from a single cell was proposed [1], the new challenges for the modern winemaking industry are focused on the application of preserved starter's microbial cultures for the optimization of the production process, the flavor characteristics and the reproducibility of the final products obtained.

In wine production, both alcoholic (AF) and malolactic (MLF) fermentations are essential to obtain high quality products [2]. Moreover, organoleptic improvement by microbial fermentation gives desirable characteristics to the final product. Thus, there is a trend towards the use not only of Saccharomyces cerevisiae and Oenococcus oeni to drive AF and MLF but also of non-Saccharomyces yeasts such as Kloeckera apiculata to improve organoleptic characteristics by producing intermediate alcohols, monoterpenes and volatile compounds [3-6].

When a single microorganism or a microbial consortium is selected as a starter culture, its conservation for subsequent use in fermentations is required. Thus, storage at low temperatures (freezing or refrigeration) and lyophilization techniques are often applied to maintain the viability of starter cultures $[7,8]$. Lyophilization is an easy way to keep a high number of viable microorganisms and the inoculation of musts using the powder forms would require a low number of procedural steps. However, this preservation process can cause cell damage leading to cell death or technological quality deterioration. These consequences can be minimized by optimizing freeze-drying conditions and using lyoprotective agents [9-12]. In addition, taking into consideration a potential large-scale production of the dry starter products, the choice of the lyoprotective agents and of the storage conditions would diminish production costs and guarantee a more practical way of inoculation.

The available data on freeze-drying involves mainly pure cultures of $S$. cerevisiae strains used in AF in wines and beers [10,11,13-15] and O. oeni $[16,17]$, but there is no information about the freeze-drying of non-Saccharomyces yeasts in pure or mixed cultures with $S$. cerevisiae strains plus O. oeni.

S. cerevisiae $\mathrm{mc}_{2}, K$. apiculata $\mathrm{mF}$ and O. oeni $\mathrm{X}_{2} \mathrm{~L}$ were previously selected for their ability to grow and metabolize sugars in simultaneous cultures under winemaking conditions, thus improving glycerol production and therefore the organoleptic properties of the endproducts [18]. In this work, we evaluated the resistance of the selected wine microorganisms in pure and mixed cultures to the lyophilization process and the maintenance of both viability and metabolic activity (AF, MLF and glycerol production) when powders were stored at different temperatures.

*Corresponding author: Sergio E Pasteris, Instituto Superior de Investigaciones Biológicas (INSIBIO), CONICET-UNT, and Instituto de Biología "Dr. Francisco D. Barbieri", Facultad de Bioquímica, Química y Farmacia, UNT, San Miguel de Tucumán, Argentina. Tel: +543814247752 ext: 7093. FAX: +543814310465 ; E-mail: pasteris@fbqf.unt.edu.ar

Received July 24, 2015; Accepted August 13, 2015; Published August 18, 2015

Citation: Ale CE, Otero MC, Pasteris SE (2015) Freeze-Drying of Wine Yeasts and Oenococcus oeni and Selection of the Inoculation Conditions after Storage. J Bioprocess Biotech 5: 248 doi:10.4172/2155-9821.1000248

Copyright: () 2015 Ale CE, et al. This is an open-access article distributed under the terms of the Creative Commons Attribution License, which permits unrestricted use, distribution, and reproduction in any medium, provided the original author and source are credited. 
The results will allow us to select lyophilization and storage conditions of potentially starter cultures formulated with indigenous yeasts and $O$. oeni strains to be used in local winemaking processes.

\section{Materials and Methods}

\section{Microorganisms}

Saccharomyces cerevisiae $\mathrm{mc}_{2}$ (an elliptic yeast) and Kloeckera apiculata $\mathrm{mF}$ (an apiculate yeast) and the lactic acid bacterium Oenococcus oeni $\mathrm{X}_{2} \mathrm{~L}$ were selected for their ability to drive the $\mathrm{AF}$ efficiently, to produce flavor compounds and to carry out the MLF, respectively. Moreover, this microbial consortium improves glycerol production [18].

\section{Culture conditions and lyoprotectants}

Growth media: $S$. cerevisiae $\mathrm{mc}_{2}$ and $K$. apiculata $\mathrm{mF}$ were grown in YEPG medium (in g/L: yeast extract, 10; peptone, 20; glucose, 20), pH 5.5 for $24 \mathrm{~h}$ at $28^{\circ} \mathrm{C}$ in microearophilia, while O. oeni $\mathrm{X}_{2} \mathrm{~L}$ was grown in MRS medium [19] supplemented with $150 \mathrm{~mL} / \mathrm{L}$ natural tomato juice (MRStj), $\mathrm{pH} 4.8$ for $24 \mathrm{~h}$ at $30^{\circ} \mathrm{C}$ in microearophilia. Tomato juice was added as a pantothenic acid source for $O$. oeni growth [20,21]. Solid media were performed by addition of $15 \mathrm{~g} / \mathrm{L}$ agar to the corresponding liquid media.

Fermentation medium: Microorganisms were grown in Natural Grape Juice (NGJ) medium (17 mL of Moscatell grape juice per liter of culture medium), $\mathrm{pH} 5.5$. This culture medium was treated at $90^{\circ} \mathrm{C}$ for $10 \mathrm{~min}$ to prevent thermal decomposition of the grape juice.

Lyoprotectant solutions: Aqueous solutions (10\% glucose, $10 \%$ fructose, $10 \%$ sucrose, $10 \%$ maltose, $10 \%$ trehalose, $2.4 \%$ sodium glutamate, $4 \%$ yeast extract, and $17 \%$ NGJ) were prepared to evaluate their lyoprotective effect on the viability of the microorganisms. All solutions were sterilized by filtration using Millipore membranes $(0.22 \mu \mathrm{m})$ with the exception of NGJ, which was treated at $90^{\circ} \mathrm{C}$ for 10 min. Cells were also resuspended in Neutral Sterilized Distilled Water (NSDW) to evaluate the intrinsic resistance of the microorganisms to the lyophilization process.

\section{Evaluation of microbial strains resistance to the lyophilization process}

Pure and mixed cultures of the strains were performed in $1000 \mathrm{~mL}$ NGJ medium and incubated at $28^{\circ} \mathrm{C}$. The different combinations of cultures and their denomination are shown in Table 1. After 24 and $72 \mathrm{~h}$ for yeast strains and $O . o e n i$, respectively, cells were collected by centrifugation $\left(3,000 \mathrm{~g}\right.$ at $4^{\circ} \mathrm{C}$ for $\left.20 \mathrm{~min}\right)$, resuspended in $10 \mathrm{~mL}$ of each lyoprotectant solution and fractionated $(300 \mu \mathrm{L})$ in eppendorf tubes. Fractions were frozen at $-20^{\circ} \mathrm{C}$ for $12 \mathrm{~h}$ and then at $-70^{\circ} \mathrm{C}$ for 1 h. Samples were lyophilized at $-50^{\circ} \mathrm{C}$ and 110 millitorr in a lyophilizer Heto FD4 (Heto-Holten, Denmark) for $48 \mathrm{~h}$. After the lyophilization process, the fractions were resuspended in $300 \mu \mathrm{L}$ NSDW and cell viability $(\mathrm{CFU} / \mathrm{mL})$ was determined. A survival factor to the lyophilization process $\left(\mathrm{SF}_{\mathrm{L}}\right)$ was defined as follows:

$$
S F_{L}=1-\left[\left(\log C F U / m L_{\text {initial }}-\log C F U / m L_{\text {final }}\right) / \log C F U / m L_{\text {initial }}\right]
$$

$\mathrm{CFU} / \mathrm{mL}_{\text {initial: }}$ : number of viable cells before the lyophilization process.

$\mathrm{CFU} / \mathrm{mL}_{\text {final }}$ : number of viable cells after the lyophilization process.

Determination of microbial growth and differential cell enumeration

Growth was evaluated by counting the number of viable cells (CFU/
$\mathrm{mL}$ ) using the decimal successive dilution method in NSDW. In order to differentiate Saccharomyces and non-Saccharomyces yeasts from mixed cultures, samples were plated on YEPG medium supplemented with ethanol $(120 \mathrm{~mL} / \mathrm{L})$, sodium metabisulphite $(0.15 \mathrm{~g} / \mathrm{L})$ and chloramphenicol $(1 \mathrm{~g} / \mathrm{L})$ for the elliptic yeast, while YEPG medium supplemented with cycloheximide $(0.01 \% \mathrm{w} / \mathrm{v})$ was used for the apiculate strain. The samples were also plated on MRStj supplemented with cycloheximide $(0.1 \% \mathrm{w} / \mathrm{v})$ to assess the growth of $\mathrm{O}$. oeni $\mathrm{X}_{2} \mathrm{~L}$. All samples were incubated at $28^{\circ} \mathrm{C}$ for 48 and $72 \mathrm{~h}$ for YEPG and MRStj media, respectively.

\section{Viability of lyophilized wine microorganisms}

After lyophilization, fractions of the powders were placed in plastic bottles with silica gel to keep them dry and stored at $4^{\circ} \mathrm{C}$ and room temperature $\left(25 \pm 2^{\circ} \mathrm{C}\right)$ for 12 months.

The number of $\mathrm{CFU} / \mathrm{mL}$ for each strain was determined as indicated above at 1, 2, 3, 6, 9 and 12 months of storage and used to calculate a survival factor to storage $\left(\mathrm{SF}_{\mathrm{s}}\right)$ for each time according to the following equation:

$$
S F_{S}=1-\left[\left(\log C F U / m L_{\text {initial }}-\log C F U / m L_{\text {final }}\right) / \log C F U / m L_{\text {initial }}\right]
$$

$\mathrm{CFU} / \mathrm{mL}_{\text {initial }}$ : number of viable cells at time $0 \mathrm{~h}$ after the lyophilization process.

$\mathrm{CFU} / \mathrm{mL}_{\text {final }}$ : number of viable cells after time $\mathrm{t}$.

\section{Maintenance of the fermentation properties of freeze-dried microorganisms during storage}

At 0, 1, 2, 3, 6, 9 and 12 months, fractions of dried microorganisms were resuspended in $100 \mu \mathrm{L}$ of NSDW, centrifuged $(3,000 \mathrm{~g}, 20 \mathrm{~min}$ ), washed twice, inoculated into $5 \mathrm{~mL}$ YEPG and MRStj media, and incubated at $28^{\circ} \mathrm{C}$ for 24 and $72 \mathrm{~h}$ for yeasts and $O$. oeni, respectively. Then, cells were harvested, washed and inoculated into $5 \mathrm{~mL} \mathrm{NGJ}$ medium to achieve initial populations of $10^{6} \mathrm{CFU} / \mathrm{mL}$ and incubated at $28^{\circ} \mathrm{C}$ up to 6 days. Finally, cell-free supernatants were obtained and stored at $-20^{\circ} \mathrm{C}$ for further analytical determinations.

\section{Analytical determinations}

Five hundred microliter fractions of cell-free supernatants were used to perform the analytical determination of malic acid consumption and products formation (ethanol, glycerol) using kits supplied by Boehringer-Mannheim, Inc. (Germany).

\section{Statistical analysis}

All experiments were performed in duplicate. Cell viability data were analyzed by an ANOVA-general linear model for analysis of residues to determine the effect of the variables (culture combination and lyoprotectant solution) and their interactions. ANOVA tests were used to quantify the effect of storage conditions (lyoprotectant solution, temperature and time) on the viability of the wine strains during 12 months of storage.

\begin{tabular}{|l|l|}
\hline Culture (denomination) & Microbial strains \\
\hline $\mathrm{SC}(1)^{*}$ & S. cerevisiae $\mathrm{mc}_{2}$ \\
\hline $\mathrm{KA}(1)$ & K. apiculata $\mathrm{mF}$ \\
\hline $\mathrm{OO}(1)$ & O. oeni $\mathrm{X}_{2} \mathrm{~L}$ \\
\hline Mixed $2^{*}(\mathrm{SC} 2-\mathrm{KA} 2)$ & S. cerevisiae $\mathrm{mc}_{2}-$ K. apiculata $\mathrm{mF}$ \\
\hline Mixed 3 (SC3-KA3-OO3) & S. cerevisiae $\mathrm{mc}_{2}-$ K. apiculata $\mathrm{mF}-\mathrm{O}$. oeni $\mathrm{X}_{2} \mathrm{~L}$ \\
\hline
\end{tabular}

"Number indicates inoculation condition: 1 , pure cultures, 2, mixed yeasts cultures and 3 , mixed yeasts and $O$. oeni culture

Table 1: Wine microorganisms in pure and mixed cultures. 
Significant differences between the mean values of each treatment were determined using Fisher's LSD or Tukey's tests (95\% confidence interval). Statistical analysis of the data was carried out with Info-Stat 2013 (student version; National University of Córdoba, Córdoba, Argentina).

\section{Results}

\section{Resistance of wine microorganisms to freeze-drying with different lyoprotectants}

A full two-factor ANOVA test of $\mathrm{SF}_{\mathrm{L}}$ considering lyoprotectant solutions $(\mathrm{L})$, culture $(\mathrm{C})$ and their interaction $(\mathrm{C} \times \mathrm{L})$ was applied. The resistance of the three microorganisms to the freeze-drying process was significantly different and depended on the lyoprotectant solutions (Table $2, \mathrm{R}^{2}=0.97-0.98$, significant $\mathrm{C} \times \mathrm{L}, P<0.0001$ ). Highest viability recovery after lyophilization was observed for O. oeni $\mathrm{X}_{2} \mathrm{~L}$ followed by $K$. apiculata $\mathrm{mF}, \mathrm{S}$. cerevisiae $\mathrm{mc}$, being the most sensitive microorganism ( $\mathrm{SF}_{\mathrm{L} \text { mean }}=0.69,0.63$ and 0.35 , respectively, Tukey's test, $P<0.05$ ) (Figure 1). Multiple comparisons of the means based on Tukey's test were used to compare the differences between the values of $\mathrm{SF}_{\mathrm{L}}$ in each lyoprotectant. The best protective effect on microbial viability was observed when using sodium glutamate $\left(\mathrm{SF}_{\mathrm{L} \text { mean }}=0.79\right.$, $P<0.05)$ while $\mathrm{SF}_{\mathrm{L}}$ mean values for the other lyoprotectants ranged between $0.46-0.64 \pm 0.02$ and they were significantly higher than those registered in NSDW $(0.34, P<0.05)$ (Figure 1$)$.

\section{Resistance of microorganisms in pure and mixed cultures to the lyophilization process}

A full two-factor ANOVA test including 9 freeze-drying media (lyoprotectans and NSDW) and 5 cultures conditions (Table 1) was performed for each strain individually. The selected strains showed a similar behavior, so that survival to freeze-drying significantly depended on the pure or mixed condition of the culture, this response being affected by the lyoprotectant (significant $\mathrm{C} \times \mathrm{L}$ interaction, $P<0.0001$ ) (Table 2).

In order to select the best conditions for the freeze-drying of the microbial strains, multiple comparisons were carried out using the mean of each individual treatment on the basis of the statistical significance of the two-way interactions between lyoprotectant and culture condition (Figure 2). For K. apiculata $\mathrm{mF}$, the best lyophilization condition was pure cultures (KA1), mainly when using sodium glutamate and sugars $\left(\mathrm{SF}_{\mathrm{L} \text { mean }}=0.93-0.85 \pm 0.03\right.$. Fisher's test, $\left.P<0.05\right)$, with the exception of maltose $\left(\mathrm{SF}_{\mathrm{man}} 0.45 \pm 0.03\right)$. When the apiculate strain was cocultured with S. cerevisiae (KA2) or S. cerevisiae + O. oeni (KA3), its survival was significantly higher in fructose $\left(\mathrm{SF}_{\mathrm{L} \text { mean }}=0.78 \pm 0.03\right.$ and $0.67 \pm 0.03$, respectively. Fisher's test, $P<0.05$ ) (Figure $2 \mathrm{~A}$ ).

For S. cerevisiae $\mathrm{mc}_{2}$, the best $\mathrm{SF}_{\mathrm{L}}$ values were obtained in mixed cultures. Thus, when the strain was co-cultured with K. apiculata $\mathrm{mF}$ (SC2), its survival was higher in maltose, NGJ, trehalose and fructose $\left(\mathrm{SF}_{\mathrm{L} \text { mean }}=0.92,0.91,0.97\right.$ and $0.70 \pm 0.04$, respectively. Fisher's test, $P<0.05)$. However, when $S$. cerevisiae $\mathrm{mc}_{2}$ was co-cultured with $K$. apiculata $\mathrm{mF}+$ O. oeni $\mathrm{X}_{2} \mathrm{~L}$ (SC3), maltose, glutamate and glucose were the best lyoprotectants $\left(\mathrm{SF}_{\mathrm{Lmean}}=0.86,0.81\right.$ and $0.69 \pm 0.04$, respectively. Fisher's test, $P<0.05$ ) (Figure $2 \mathrm{~B}$ ).

With respect to O. oeni $\mathrm{X}_{2} \mathrm{~L}$, the highest values of $\mathrm{SF}_{\mathrm{L}}$ were detected when cells from pure cultures were resuspended in NGJ and sodium glutamate $\left(\mathrm{SF}_{\mathrm{L} \text { mean }}=0.93\right.$ and $0.90 \pm 0.03$, respectively. Fisher's test, $P<$ $0.05)$. When the LAB strain was co-cultured with yeast strains, sucrose, trehalose, sodium glutamate, glucose and maltose had a significantly higher protective effect than the other lyoprotectans $\left(\mathrm{SF}_{\mathrm{L} \text { mean }}=0.86\right.$ to $0.73 \pm 0.03$. Fisher's test, $P<0.05$ ) (Figure $2 \mathrm{C}$ )

\section{Effect of storage on the viability of lyophilized microorganisms}

In order to determine the degree of survival of wine microorganisms to freeze-drying with different lyoprotectants during their storage $\left(\mathrm{SF}_{\mathrm{s}}\right)$, a full four-factor ANOVA test was applied. The test included culture (pure and mixed), lyoprotectant solution, time $(1,2,3,6,9$ and 12 months) and temperature $\left(4\right.$ and $25 \pm 2^{\circ} \mathrm{C}$ ) of storage. The sum of squares (SS) of 84.12 over a total of 86.76 indicated that the model satisfactorily explains the behavior of the microbial system and exhibits the main interactions between different factors. The survival of the freeze-dried microorganisms during storage was significantly affected by the culture condition (pure or mixed cultures) and depended on the lyprotectant used $(S S=11.97, P<0.0001)$ (Table 3). Moreover, SFs was also influenced by storage time (Table $4, \mathrm{SS}=35.82$ for $\mathrm{C} \times \mathrm{L}$ interaction, $P<0.0001$ ).

When the analysis of $\mathrm{C} \times \mathrm{L}$ interaction was considered, all lyoprotectants showed at least one $\mathrm{SF}_{\mathrm{S}}$ mean value above the general median value with the exception of NSDW, in which the best $\mathrm{SF}_{\mathrm{S}}$ value $(0.31 \pm 0.01)$ was found for the LAB strain in pure cultures $(\mathrm{O} 1)$ (Figure 3$)$.

The $\mathrm{SF}_{\mathrm{S}}$ of $\mathrm{S}$. cerevisiae $\mathrm{mc}_{2}$ co-cultured with $K$. apiculata $\mathrm{mF}$ (S2) lyophilized in maltose was significantly higher than with the other lyoprotectants used ( $\mathrm{SFs}_{\text {mean }}=0.81 \pm 0.01$. Fisher's test, $P<0.05$ ); this co-culture condition was also favorable for the elliptic yeast in NGJ $\left(\mathrm{SFs} s_{\text {mean }}=0.75 \pm 0.01\right)$. A similar $\mathrm{SF}_{\mathrm{S}}$ value $(0.74 \pm 0.01)$ was observed for the LAB strain in pure culture when lyophilized and stored in NGJ. However, K. apiculata $\mathrm{mF}$ showed satisfactory survival values when lyophilized and stored as pure cultures (K1) in all sugar solutions (SFs $=0.74$ to $0.62 \pm 0.01$ ) with the exception of maltose $\left(\mathrm{SFs}_{\text {mean }}=0.34\right.$ \pm 0.01 ) (Figure 3).

When $K$. apiculata $\mathrm{mF}(\mathrm{K} 2)$ was lyophilized in a mixed culture with $S$. cerevisiae $\mathrm{mc}_{2}(\mathrm{~S} 2)$, all the $\mathrm{SF}_{\mathrm{S}}$ values obtained when using the lyoprotectant solutions were below the general median (0.40), with the exception of fructose $\left(\mathrm{SFs}_{\text {mean }}=0.62 \pm 0.01\right)$. Thus, considering $\mathrm{SF}_{\mathrm{s}}$ values above 0.5 , this co-culture lyophilized in fructose $\left(\mathrm{SF}_{S \text { mean }}=0.62\right.$ and $0.51 \pm 0.01$ for $\mathrm{K} 2$ and $\mathrm{S} 2$, respectively. Fisher's test, $P<0.05$ ) showed satisfactory viability during storage. On the other hand, when the three microorganisms were co-cultured and lyophilized, no acceptable SFs values (above 0.5 ) were found for any of the strains when using the

\begin{tabular}{|c|c|c|c|c|c|c|c|c|c|c|c|c|}
\hline \multirow{2}{*}{ Source of variation } & \multicolumn{4}{|c|}{ K. apiculata $\mathrm{mF}\left(\mathrm{R}^{2}=0.98\right)^{*}$} & \multicolumn{4}{|c|}{ S. cerevisiae $\mathrm{mc}_{2}\left(\mathrm{R}^{2}=0.97\right)$} & \multicolumn{4}{|c|}{ O. oeni $\mathrm{X}_{2} \mathrm{~L}\left(\mathrm{R}^{2}=0.98\right)$} \\
\hline & ss & DF & MS & F-Stat & ss & DF & MS & F-Stat & SS & DF & MS & F-Stat \\
\hline Model & 2.51 & 26 & 0.10 & $56.49^{*}$ & 3.12 & 26 & 0.12 & $32.99^{*}$ & 1.22 & 17 & 0.07 & $41.72^{*}$ \\
\hline Culture (C) & 0.51 & 2 & 0.26 & $149.95^{*}$ & 0.38 & 2 & 0.19 & $52.68^{*}$ & 0.06 & 1 & 0.06 & $33.18^{*}$ \\
\hline Lyoprotectant (L) & 1.3 & 8 & 0.16 & $95.13^{*}$ & 1.59 & 8 & 0.2 & $54.66^{*}$ & 0.67 & 8 & 0.08 & $48.73^{*}$ \\
\hline$C \times L$ & 0.7 & 16 & 0.04 & $25.49^{*}$ & 1.15 & 16 & 0.07 & $19.70^{\star}$ & 0.49 & 8 & 0.06 & $35.78^{*}$ \\
\hline Residuals & 0.05 & 27 & 0.0017 & & 0.1 & 27 & 0.0036 & & 0.03 & 18 & 0.0017 & \\
\hline
\end{tabular}

${ }^{*} P<0.0001$. Sum of squares (SS), Degrees of freedom (DF), Mean squares (MS), F-Statistical (F-Stat)

Table 2: ANOVA test applied for all factors (culture and lyoprotectant solution) and their interaction on cell viability (Survival Factor to lyophilization, $\mathrm{SF}_{\mathrm{L}}$ ). 


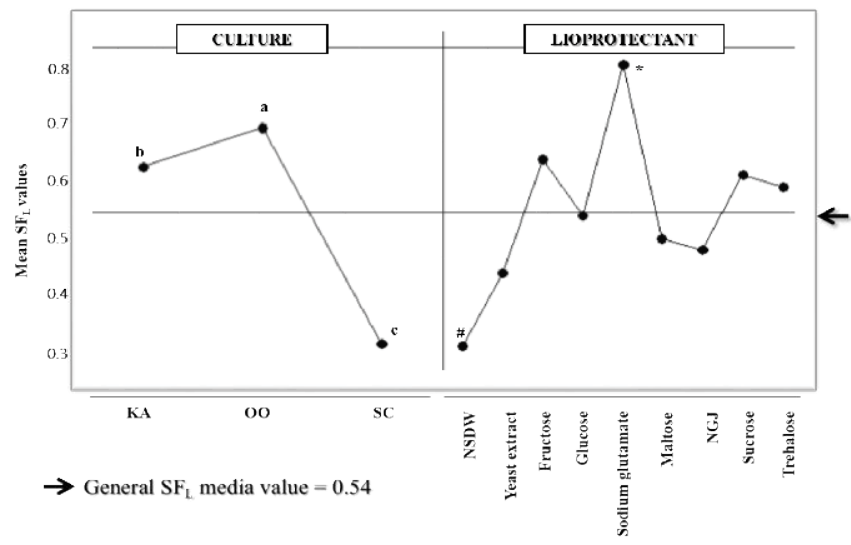

Figure 1: Effect of strain-lyoprotectant interaction on survival factor to lyophilization $\left(\mathrm{SF}_{\mathrm{L}}\right)$

$\mathrm{KA}$ : Kloeckera apiculata $\mathrm{mF}$, SC: Saccharomyces cerevisiae $\mathrm{mc}_{2}$, OO: Oenococcus oeni $\mathrm{X}_{2} \mathrm{~L}$. ${ }^{\mathrm{a}, \mathrm{b}, \mathrm{c}}$ indicate significant differences between mean SF values. "Significantly higher value. "Significantly lower value.
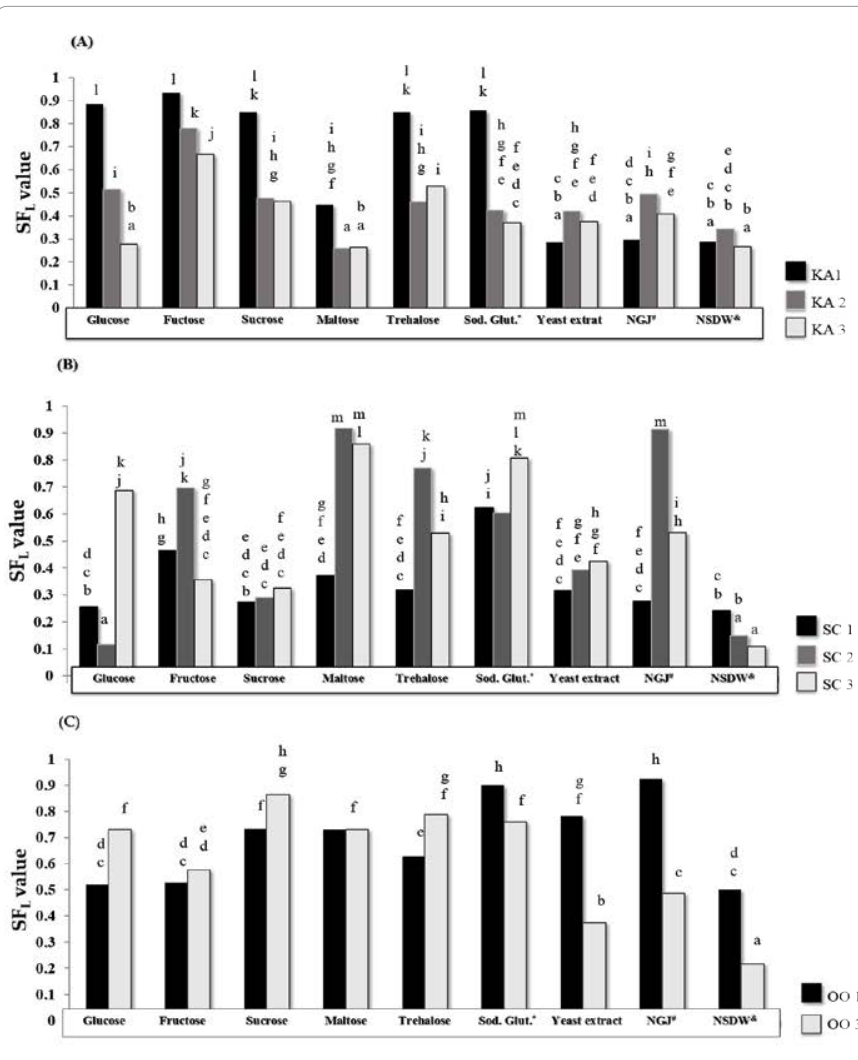

Lyoprotectants

Figure 2: Survival of wine microorganisms in different lyoprotectants after freeze-drying

(A): KA- K. apiculata mF, (B): SC- S. cerevisiae $\mathrm{mc}_{2},(\mathrm{C})$ : OO- O. oeni $\mathrm{X}_{2} \mathrm{~L} .1$ Pure cultures, 2-Yeast mixed cultures, 3- wine microorganisms mixed cultures. "Sod. Glut.: Sodium Glutamate, "NGJ: Natural Grape Juice, " NSDW: Neutral Sterilized Distilled Water.

same lyoprotectant (Figure 3).

O. oeni $\mathrm{X}_{2} \mathrm{~L}$ showed optimal SFs values when pure cultures $(\mathrm{O} 1)$ were lyophilized in NGJ, sodium glutamate and yeast extract $(0.74,0.72$ and $0.62 \pm 0.01$, respectively) (Figure 3 ).
With respect to the $\mathrm{C} \times \mathrm{t}$ interaction (Table 3 and Figure 4), an important decrease in cell viability during the storage period was observed, which was culture-dependent (ANOVA test, $P \leq 0.0001$ ) (Table 3). O. oeni $\mathrm{X}_{2} \mathrm{~L}$ in pure and mixed cultures (O1 and $\left.\mathrm{O} 3\right)$, S. cerevisiae $\mathrm{mc}_{2}$ in mixed cultures (S2 and $\mathrm{S} 3$ ) and $K$. apiculata $\mathrm{mF}$ in pure cultures (K1) represented the optimal storage conditions for lyophilized strains. In these culture conditions, $\mathrm{SF}_{\mathrm{S}}(0.69$ to $0.39 \pm 0.01)$ up to 6 months of storage were close to the general median value $(0.40 \pm 0.01)$ and were significantly higher than with the other culture conditions (S1, K2 and K3) with the same storage time $(P \leq 0.05)$ (Figure 4$)$.

The effect of storage time on microbial survival was conditioned by temperature (significant $\mathrm{T} \times \mathrm{t}$ interaction, $P \leq 0.0001$ ) (Table 3 ). Up to 9 months of storage, $\mathrm{SF}_{\mathrm{S}}$ values at $25^{\circ} \mathrm{C}$ for each time were significantly lower $(P \leq 0.05)$ than those registered at $4^{\circ} \mathrm{C}$. Moreover, at $25^{\circ} \mathrm{C}$, SFs values were below the general median $(0.40 \pm 0.01)$ since 3 months of storage. However, at $4^{\circ} \mathrm{C}$, SFs values were above the general median up to 6 months of storage (Figure 5).

\section{Maintenance of fermentative abilities of wine microorganisms during 12 months of storage}

The behavior of $S$. cerevisiae $\mathrm{mc}_{2}, K$. apiculata $\mathrm{mf}$ and $O$. oeni $\mathrm{X}_{2} \mathrm{~L}$ during 12 months of storage at 4 and $25^{\circ} \mathrm{C}$ was analyzed in lyophilized strains in $10 \%$ fructose for Kloeckera apiculata-S. cerevisiae (KA2-SC2) and $17 \%$ NGJ for Oenococcus oeni (O1).

The fermentation ability of lyophilized strains in NGJ and fructose when inoculated in simultaneous cultures was evaluated. Thus, malic acid consumption and ethanol/glycerol production were significantly affected by both storage time and temperature (Table 4, ANOVA test).

Malolactic activity was lower in microbial systems stored at $4^{\circ} \mathrm{C}$ than in those stored at $25^{\circ} \mathrm{C}(1.81 \pm 0.02$ and $1.87 \pm 0.02 \mathrm{mmol} / \mathrm{L}$, respectively. Fisher's test, $P<0.05)$ while glycerol and ethanol production were higher at $4^{\circ} \mathrm{C}(1.9 \pm 0.02$ and $155 \pm 0.2 \mathrm{mmol} / \mathrm{L}$, respectively) than at $25^{\circ} \mathrm{C}(1.82 \pm 0.02$ and $148.08 \pm 0.2 \mathrm{mmol} / \mathrm{L}$, respectively $)$.

The dried microorganisms stored at $4^{\circ} \mathrm{C}$ showed minimal differences between their malic acid consumption patterns $(1.75 \pm 0.04$ to $2.1 \pm 0.04 \mathrm{mmol} / \mathrm{L}, P<0.05$ ), a significant effect being observed only at 9 months $(1.62 \pm 0.04 \mathrm{mmol} / \mathrm{L}, P<0.05)$ (Figure 6).

Ethanol production gradually diminished during storage, lowest concentrations being found at 12 months $(152.5 \pm 0.48 \mathrm{mmol} / \mathrm{L}$, $P<0.05$ ) (Figure 6). Glycerol production remained stable up to 12 months and no significant differences were found with respect to 1 month of storage (1.82 \pm 0.05 to $2.02 \pm 0.05 \mathrm{mmol} / \mathrm{L}$ ) (Figure 6).

\section{Discussion}

The design of starter cultures in industry should consider not only the optimization of the fermentative process but also the way of administration for medium and large scale production as well as the storage facilities that ensure the maintenance of microbial viability and its metabolic capability over time.

Due to all the factors affecting the resistance of microorganisms to lyophilization and storage, there are numerous strategies to reduce cell damage during the process such as controlling thermal and kinetic parameters and/or using lyoprotectants (sugars, amino acids, protein compounds and antioxidant molecules) to increase microbial survival rate [22-25].

In this work, the resistance of $S$. cerevisiae $\mathrm{mc}_{2}, K$. apiculata $\mathrm{mF}$ and O. oeni $\mathrm{X}_{2} \mathrm{~L}$ in pure and mixed cultures to lyophilization and to storage 


\begin{tabular}{|c|c|c|c|c|c|}
\hline Source of variation & ss & DF & MS & F-stat & $P$-value \\
\hline Model & 84.12 & 863 & 0.10 & $31.90^{\star}$ & $<0.0001$ \\
\hline Culture (C) & 12.91 & 7 & 1.84 & $603.59^{*}$ & $<0.0001$ \\
\hline Temperature (T) & 0.38 & 1 & 0.38 & $123.35^{*}$ & $<0.0001$ \\
\hline Lyoprotectant (L) & 18.54 & 8 & 2.32 & $758.31^{*}$ & $<0.0001$ \\
\hline Time $(\mathrm{t})$ & 11.97 & 5 & 2.39 & $783.09^{*}$ & $<0.0001$ \\
\hline $\mathrm{C} \times \mathrm{T}$ & 0.08 & 7 & 0.01 & $3.93^{*}$ & 0.0003 \\
\hline$C \times L$ & 35.82 & 56 & 0.64 & $209.34^{*}$ & $<0.0001$ \\
\hline $\mathrm{C} \times \mathrm{t}$ & 0.68 & 35 & 0.02 & $6.31^{*}$ & $<0.0001$ \\
\hline $\mathrm{T} \times \mathrm{L}$ & 0.04 & 8 & $4.7 \times 10^{-3}$ & $1.53^{*}$ & 0.143 \\
\hline $\mathrm{T} \times \mathrm{t}$ & 0.50 & 5 & 0.10 & $32.54^{\star}$ & $<0.0001$ \\
\hline $\mathrm{L} \times \mathrm{T}$ & 0.21 & 40 & 0.01 & $1.74^{\star}$ & 0.0036 \\
\hline$C \times T \times L$ & 0.27 & 56 & $4.8 \times 10^{-3}$ & $1.59^{*}$ & 0.0049 \\
\hline $\mathrm{C} \times \mathrm{T} \times \mathrm{t}$ & 0.15 & 35 & $4.2 \times 10^{-3}$ & $1.38^{*}$ & 0.0717 \\
\hline$C \times L \times t$ & 1.09 & 280 & $3.9 \times 10^{-3}$ & $1.28^{*}$ & 0.0047 \\
\hline$T \times L \times t$ & 0.09 & 40 & $2.3 \times 10^{-3}$ & $0.76^{*}$ & 0.8593 \\
\hline$C \times t \times L$ & 0.26 & 280 & $9.3 \times 10^{-4}$ & $0.31^{*}$ & $>0.9999$ \\
\hline Residual & 2.64 & 864 & $3.1 \times 10^{-3}$ & & \\
\hline Total & 86.76 & 1727 & & & \\
\hline
\end{tabular}

${ }^{*} P<0.0001$. Sum of squares (SS), Degrees of freedom (DF), Mean squares (MS), F-Statistical (F-Stat)

Table 3: ANOVA test applied for all factors (culture, temperature, lyoprotectant, time) and their interaction on cell viability (Survival Factor to storage, $\mathrm{SF}_{\mathrm{S}}$ ).

\begin{tabular}{|c|c|c|c|c|c|c|c|c|c|c|c|c|}
\hline \multirow{2}{*}{$\begin{array}{l}\text { Source of } \\
\text { variation }\end{array}$} & \multicolumn{4}{|c|}{$\begin{array}{l}\text { Malic acid consumption } \\
\qquad\left(R^{2}=0.95\right)^{*}\end{array}$} & \multicolumn{4}{|c|}{$\begin{array}{l}\text { Ethanol production } \\
\qquad\left(R^{2}=0.98\right)^{\star}\end{array}$} & \multicolumn{4}{|c|}{$\begin{array}{l}\text { Glycerol production } \\
\left(R^{2}=0.81\right)^{\star}\end{array}$} \\
\hline & ss & DF & MS & F-Stat & ss & DF & MS & F-Stat & ss & DF & MS & F-Stat \\
\hline Model & 0.77 & 11 & 0.07 & $19.65^{*}$ & 348.46 & 11 & 31.68 & $69.12^{*}$ & 0.21 & 11 & 0.02 & $4.58^{\#}$ \\
\hline Temperature $(\mathrm{T})$ & 0.02 & 1 & 0.02 & $5.41^{\#}$ & 287.04 & 1 & 287.04 & $626.27^{\star}$ & 0.04 & 1 & 0,04 & $9.16^{\#}$ \\
\hline Time $(\mathrm{t})$ & 0.56 & 5 & 0.11 & $31.67^{\star}$ & 54.71 & 5 & 10.94 & $23.87^{\star}$ & 0.13 & 5 & 0.03 & $6.06^{\#}$ \\
\hline $\mathrm{T} \times \mathrm{t}$ & 0.19 & 5 & 0.04 & $10.48^{\#}$ & 6.71 & 5 & 1.34 & 2.93 & 0.05 & 5 & 0.01 & 2.18 \\
\hline Residuals & 0.04 & 12 & $3.6 \times 10^{-3}$ & & 5.50 & 12 & 0.46 & & 0.05 & 12 & $4.2 \times 10^{-3}$ & \\
\hline
\end{tabular}

P $<0.0001,{ }^{\#} P<0.05$. Sum of squares (SS), Degrees of freedom (df), Mean squares (MS), F-Statistical (F-Stat)

Table 4: ANOVA test for all factors (storage temperature and time) and their interaction on malic acid consumption and ethanol / glycerol production by dried $K$. apilculata $\mathrm{mF}, \mathrm{S}$. cerevisiae $\mathrm{mc}_{2}$ and O. oeni $\mathrm{X}_{2} \mathrm{~L}$.

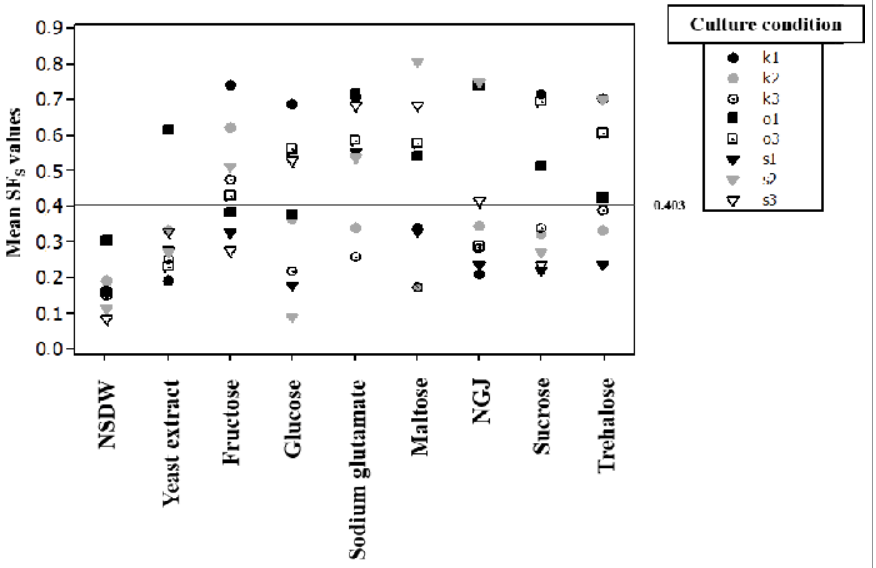

Figure 3: Effect of culture-lyoprotectant $(C \times L)$ interaction on survival factor to storage $\left(\mathrm{SF}_{\mathrm{s}}\right)$.

temperatures $\left(4\right.$ and $25^{\circ} \mathrm{C}$ ) for 12 months was evaluated. The choice of lyoprotectants was made considering that the final organoleptic characteristics of the wine should be unaffected by their addition, that they should be easily available in the local industry, and that they should be inexpensive.

Microbial survival to the lyophilization process depends on various factors such as density, physiological status of the microorganisms and rehydration conditions of the powder forms [8]. In order to eliminate their interference, in this work we standardized pre-lyophilization (initial cell concentration of selected wine microorganisms, age of pure and mixed cultures) and rehydration (medium, temperature, volume and time) procedures.

For a systematic assessment of microorganism viability after lyophilization and during storage, survival factors for resistance to lyophilization $\left(\mathrm{SF}_{\mathrm{L}}\right)$ and storage $\left(\mathrm{SF}_{\mathrm{S}}\right)$ were defined. These equations include logarithmic data, which would be a good approach to the biological systems behavior $[25,26]$.

Intrinsic microbial resistance was evaluated in water (NSDW) under the same drying and storage conditions. In all cases, both $\mathrm{SF}_{\mathrm{L}}$ and $\mathrm{SF}_{S}$ values were significantly lower than those obtained with lyoprotectants (Figure 1 ). Overall, the $\mathrm{R}^{2}>0.9$ values obtained using the tests applied in this work satisfactorily describe the systems designed for all factors evaluated and their interactions.

With respect to survival to lyophilization $\left(\mathrm{SF}_{\mathrm{L}}\right)$, the microbial system showed significant differences for each strain. The behavior observed in the general means to $\mathrm{SF}_{\mathrm{L}}$ for each strain in the different conditions shared similar patterns to those found for active cells during fermentation with S. cerevisiae, K. apiculata and O. oeni strains, in which highest viability corresponded to $O$. oeni, followed by $K$. apiculata and S. cerevisiae $[18,27,28]$. 


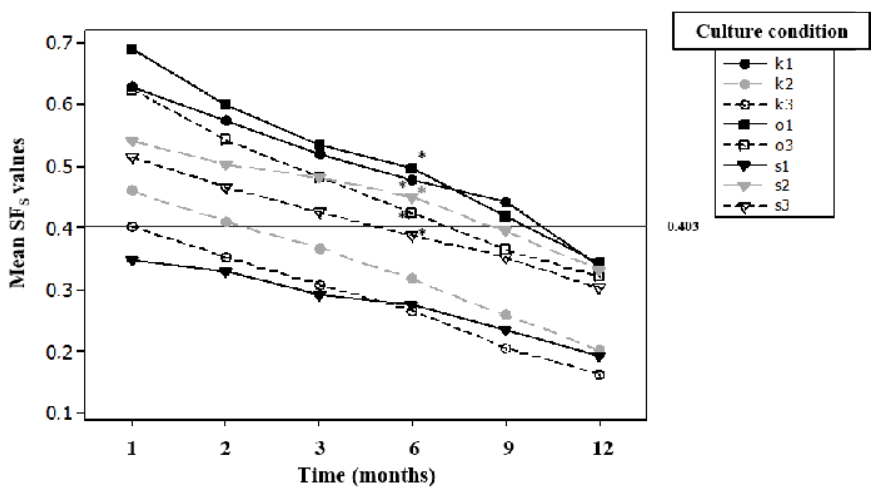

Figure 4: Effect of culture-time $(C \times t)$ interaction on survival factor to storage $\left(\mathrm{SF}_{\mathrm{S}}\right)$

"indicates significant differences with respect to the others at 6 months of storage.

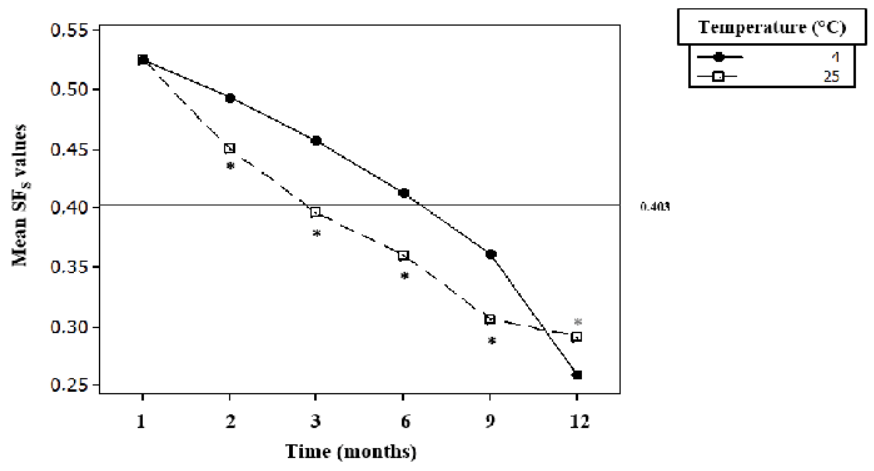

Figure 5: Effect of temperature-time $(T \times t)$ interaction on survival factor to storage $\left(\mathrm{SF}_{\mathrm{s}}\right)$.

*Indicates significant differences between each temperature at the same time.

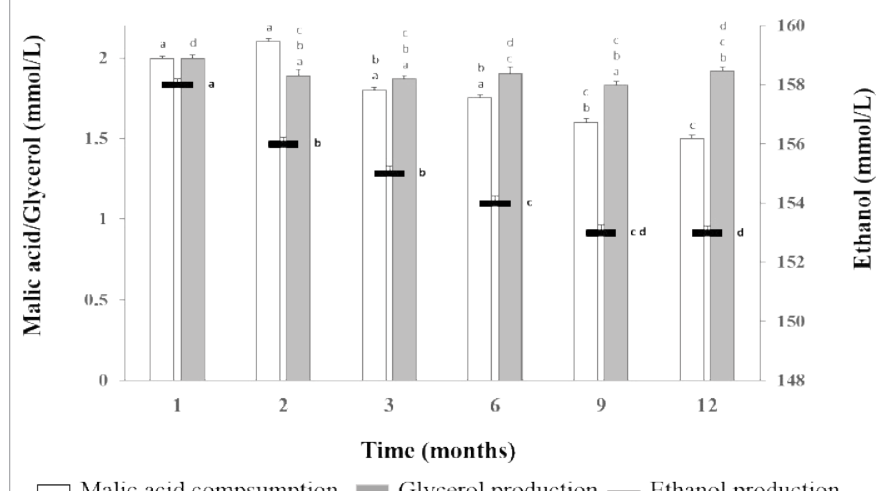

Figure 6: Evaluation of fermentative properties and glycerol production of dried mixed strains maintained at $4^{\circ} \mathrm{C}$ for 12 months*.

${ }^{*}$ Results obtained with dry cultures of $S$. cerevisiae $\mathrm{mc}_{2}-K$. apiculata in $10 \%$ fructose (SC2-KA2) and O. oeni $\mathrm{X}_{2} \mathrm{~L}$ in $10 \%$ NGJ (OO1). ${ }^{\mathrm{a}, \mathrm{b}, \mathrm{c}, \mathrm{d}, \mathrm{din}}$ dicate significant differences between the final concentrations of malic acid and products (ethanol and glycerol) from dried strains after simultaneous inoculation in NGJ.

As to the dependence of $\mathrm{SF}_{\mathrm{L}}$ on the lyoprotectant, sodium glutamate was the best protective agent. However, when lyoprotectant and culture conditions (Table 1) were evaluated, sugars afforded fairly good protection $\left(\mathrm{SF}_{\mathrm{L}} \geq 0.5\right)$ for $K$. apiculata $\mathrm{mF}$ and O. oeni. Only fructose, maltose and trehalose were appropriate for S. cerevisiae mc2 and its protection was culture-dependent (Table 2, $\mathrm{C} \times \mathrm{L}$ interaction). Sucrose and trehalose are used to preserve cell structure and function during drying by preventing protein denaturation $[29,30]$. Trehalose, a non-metabolizable sugar known to possess protective properties [3134], was used in this work as a reference sugar for the lyophilization process. This sugar is more suitable to preserve microbial strains at the laboratory scale due to its high cost. However, it should be noted that trehalose registered similar $\mathrm{SF}_{\mathrm{L}}$ values to those of other high-availability sugars. Similarly, sodium glutamate is widely used in the lyophilization processes of microorganisms for the food industry $[8,9,35,36]$ because of its well-known protective capacity. However, its high cost led us to consider sucrose and fructose since they afford a medium to high protective effect and are products from the regional sugarcane industry $[37,38]$.

On the basis of these observations, in order to optimize the drying process by decreasing the volume of cultures and using inexpensive matrices, the lyophilization of the cells from SC-KA cultures with fructose provides a good recovery of viability of both wine yeasts after the process and represents a practical and inexpensive inoculation alternative. Since NGJ showed good protective effect on $O$. oeni in pure cultures, it would represent a cheaper lyoprotectant than sodium glutamate and is a common substrate in wineries [39,40]. Complex matrices as lyoprotectant have been applied for freeze-drying of food microorganisms and most of them include milk-derived compounds or combinations with milk [35,41-43]. These compounds were not used in this work because they would affect both fermentation performance and wine quality.

Taking into account the maintenance of cell viability during storage, microbial populations were studied for 12 months considering culture condition and storage time and temperature. With respect to the culture condition, in most cases K. apiculata $\mathrm{mF}$ and $O$. oeni showed a better resistance to storage in pure cultures (KA1, OO1), while $S$. cerevisiae $\mathrm{mc}_{2}$ was more resistant in mixed culture with K. apiculata $\mathrm{mF}$ (Table 1, SC2). It is important to point out that the culture combinations $\mathrm{SC} 2-\mathrm{OO} 2$ and $\mathrm{KA} 2-\mathrm{OO} 2$ were not carried out because the times of exponential growth culture for yeasts and O. oeni are different. Therefore, $48 \mathrm{~h}$ for yeasts and $72 \mathrm{~h}$ for the LAB strain are necessary to obtain an active microbial population to start the fermentation process after rehydration. On the other hand, $\mathrm{KA} 2-\mathrm{OO} 2$ is not a practical combination. Although there is a trend toward the use of non-Saccharomyces yeasts in winemaking, their fermentation power is lower than that of Saccharomyces yeasts [44], thus the incorporation of non-Saccharomyces strains in starter cultures aims at improving the organoleptic characteristics of wine and not at replacing the Saccharomyces strains $[45,46]$. However, when the three microorganisms were co-cultured, yeast growth rate showed a slight decrease and the stationary growth phase was achieved between 72

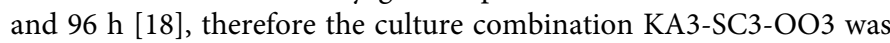
carried out and cells were harvested at $72 \mathrm{~h}$ of incubation. The use of a single mixed culture would allow the optimization of the whole process by diminishing production costs and favoring one-step inoculation of dried starter cultures.

Taking into account the effect of storage time ( $t$ ) on the viability of the selected strains, a general $\mathrm{SF}_{\mathrm{S}}$ median considering 12 months of storage was defined. Therefore, this information covers the statistical data at any time up to one year of storage. A general median of 0.403 suggests that 6 months of storage would be a reliable period to maintain appropriate microbial counts. Although at this time KA1, 
SC2 and OO1 were the best cultures to store the strains, SC2 was not independent of KA2, which was under the general median with $\mathrm{SF}_{\mathrm{S}}$ values of about 0.35 . Taking into account that $S$. cerevisiae drives AF and $K$. apiculata provides organoleptic characteristics to wines [46,47], its lower proportion would contribute to the sensorial profile of wines, thus the KA2-SC2 combination would be appropriate for lyophilization and storage.

The influence of temperature on the viability of dried microorganisms has a critical impact and thus represents a factor of interest $[8,12,48-50]$. In this work, we detected higher viability values at $4^{\circ} \mathrm{C}$ than at room temperature $\left(25^{\circ} \mathrm{C}\right)$, with the exception of 12 months. This last modification induced the significant effect of $\mathrm{T} \times \mathrm{t}$ interaction in SFs variability (Table 5). Consequently, we propose a storage time of up to 6 months, so this change in behavior in $\mathrm{SF}_{\mathrm{S}}$ during 9-12 months period would not be considered.

Taking into account the influence of lyoprotectant solutions on $\mathrm{SF}_{\mathrm{L}}$ and $\mathrm{SF}_{\mathrm{s}}$, we selected the best combination of culture condition/ lyoprotectant solution/ storage temperature to study the maintenance of fermentation capability of microorganisms in both pure and mixed cultures by evaluating AF (ethanol production), MLF (malic acid consumption) and glycerol synthesis. Lyoprotectant solutions costs and their availability in the local industry were also considered. Therefore, the combined culture KA2-SC2 lyophilized in 10\% fructose and $\mathrm{OO} 1$ in $17 \%$ NGJ were selected to inoculate the strains in NGJ medium in order to evaluate their metabolic activity. Overall, neither malic acid consumption nor glycerol production showed significant differences when fermentations were performed with cultures stored up to 12 months; however, ethanol production diminished after 6 months of storage.

To the best of our knowledge, there are no reports concerning resistance to freeze-drying of mixed cultures of yeast $S$. cerevisiae and non-Saccharomyces together with $O$. oeni and their viability during storage. However, previous studies reported the survival and maintenance of the absorption capacity of volatile compounds of pure cultures of $S$. cerevisiae Lallemand" BM45 after lyophilization in sterile distilled water and subsequent inoculation in synthetic wine medium [7]. Other authors evaluated the survival of pure cultures of $S$. cerevisiae when lyophilized in dry rice cake and dry plant fiber strands [50] as well as $\mathrm{O}$. oeni $\mathrm{H}-2$ by using $2.5 \%$ sodium glutamate [8]. In addition, there are few studies on freeze-drying of mixed microbial cultures for use in the food industry. Thus, Bolla et al. [51] described the viability and probiotic properties of a starter culture formulated with Lactobacillus kefir, L. plantarum, Lactococcus lactis, S. cerevisiae and Kluyveromyces marxianus isolated from kefir when lyophilized in UHT milk and fermented milk supplemented with $300 \mathrm{mmol} / \mathrm{L}$ sucrose or trehalose and stored at $4^{\circ} \mathrm{C}$ for 6 months. Also, Rathnayaka [43] reported the viability and maintenance of beneficial properties of mixed cultures of $L$. rhamnosus and L. plantarum when lyophilized in UHT milk and supplemented with $300 \mathrm{mmol} / \mathrm{L}$ trehalose, sorbitol or sucrose and stored at $4^{\circ} \mathrm{C}$ for 6 months.

On the basis of the results obtained, we suggest the simultaneous inoculation of $K$. apiculata $\mathrm{mF}$ and S. cerevisiae $\mathrm{mc}_{2}$ lyophilized in $10 \%$ fructose and O. oeni $\mathrm{X}_{2} \mathrm{~L}$ in $17 \%$ NGJ up to 6 months of storage at $4^{\circ} \mathrm{C}$. Therefore, an efficiently AF, MLF and increased glycerol concentration due to presence of the apiculate strain would be achieved by improving the organoleptic characteristics of wines. However, further studies are required to evaluate the performance of dried microorganisms when inoculated into grape musts for small, medium and large scale production.

\section{Acknowledgements}

This research was supported by grants from Consejo de Investigaciones de la Universidad Nacional de Tucumán (26/D 436) and Agencia Nacional de Promocion Científica y Tecnológica (PICT 847).

\section{References}

1. Pretorius IS (2000) Tailoring wine yeast for the new millennium: novel approaches to the ancient art of winemaking. Yeast 16: 675-729.

2. Davis CR, Wibowo D, Eschenbruch R, Lee TH, Fleet GH (1985) Practical implications of malolactic fermentation: a review. Am J Enol Vit 36: 290-301.

3. Clemente-Jimenez JM, Mingorance-Cazorla L, Martínez-Rodríguez S, Las Heras-Vázquez FJ, Rodríguez-Vico F (2004) Molecular characterization and oenological properties of wine yeasts isolated during spontaneous fermentation of six varieties of grape must. Food Microbiol 21: 149-155.

4. Jolly N, Augustyn O, Pretorius IS (2006) The role and use of non-Saccharomyces yeasts in wine production. S Afr J Enol Vitic 27: 15-39.

5. Hernández-Orte $P$, Cersosimo M, Loscos N, Cacho J, Garcia-Moruno E, et al. (2008) The development of varietal aroma from non-floral grapes by yeasts of different genera. Food Chem 107: 1064-1077.

6. Rodríguez ME, Lopes CA, Barbagelata RJ, Barda NB, Caballero AC (2010) Influence of Candida pulcherrima Patagonian strain on alcoholic fermentation behaviour and wine aroma. Int J Food Microbiol 138: 19-25.

7. Pradelles R, Vichi S, Alexandre H, Chassagne D (2009) Influence of the drying processes of yeasts on their volatile phenol sorption capacity in model wine. In J Food Microbiol 135: 152-157.

8. Zhao G, Zhang G (2005) Effect of protective agents, freezing temperature rehydration media on viability of malolactic bacteria subjected to freeze-drying J Appl Microbiol 99: 333-338.

9. Berny JF, Hennebert GL (1991) Viability and stability of yeast cells and fiamentous fungus spores during freeze-drying: effect of protectants and cooling rate. Mycologia 83: 805-815

10. Lodato P, Se govia de Huergo M, Buera MP (1999) Viability and therma stability of a strain of Saccharomyces cerevisiae freeze-dried in different sugar and polymer matrices. Appl Microbiol Biotechnol 52: 215-220.

11. Cerrutti $P$, Segovia de Huergo $M$, Galvagno $M$, Schebor $C$, del Pilar Buera $M$ (2000) Commercial baker's yeast stability as affected by intracellular content of trehalose, dehydration procedure and the physical properties of external matrices. Appl Microbiol Biotechnol 54: 575-580.

12. Abadias M, Benabarre A, Teixidó N, Usall J, Viñas I (2001) Effect of freeze drying and protectants on viability of the biocontrol yeast Candida sake. Int $J$ Food Microbiol 65: 173-182.

13. Beney L, Martínez de Marañón I, Marechal PA, Gervais P (2000) Influence of thermal and osmotic stresses on the viability of the yeast Saccharomyces cerevisiae. Int J Food Microbiol 55: 275-279.

14. Miyamoto-Shinohara Y, Sukenobe J, Imaizumi T, Nakahara T (2006) Survival curves for microbial species stored by freeze-drying. Cryobiology 52: 27-32.

15. Kandylis P, Drouza C, Bekatorou A, Koutinas AA (2010) Scale-up of extremely low temperature fermentations of grape must by wheat supported yeast cells. Bioresour Technol 101: 7484-7491.

16. Li H, Zhao W, Wang $\mathrm{H}$, Li ZC, Wang AL (2009) Influence of culture $\mathrm{pH}$ on freeze-drying viability of Oenococcus oeni and its relationship with fatty acid composition. Food Bioprod Process 87: 56-61.

17. Maicas S, Pardo I, Ferrer S (2000) The effects of freezing and freeze-drying of Oenococcus oeni upon induction of malolactic fermentation in red wine. Int $J$ Food Sci Technol 35: 75-79.

18. Ale CE, Farías ME, Strasser de Saad AM, Pasteris SE (2014) Glycerol production by Oenococcus oeni during sequential and simultaneous cultures with wine yeast strains. J Basic Microbiol 54 Suppl 1: S200-209.

19. de Man JC, Rogosa M, Sharpe E (1969) A medium for cultivation of lactobacilli. J Appl Bacteriol 23: 130-145

20. Dicks LM, Dellaglio F, Collins MD (1995) Proposal to reclassify Leuconostoc oenos as Oenococcus oeni [corrig.] gen. nov., comb. nov. Int J Syst Bacteriol 45: 395-397. 
Citation: Ale CE, Otero MC, Pasteris SE (2015) Freeze-Drying of Wine Yeasts and Oenococcus oeni and Selection of the Inoculation Conditions after Storage. J Bioprocess Biotech 5: 248 doi:10.4172/2155-9821.1000248

21. Richter H, Vlad D, Unden G (2001) Significance of pantothenate for glucose fermentation by Oenococcus oeni and for suppression of the erythritol and acetate production. Arch Microbiol 175: 26-31.

22. Huang L, Lu Z, Yuan Y, Lü F, Bie X (2006) Optimization of a protective medium for enhancing the viability of freeze-dried Lactobacillus delbrueckii subsp. bulgaricus based on response surface methodology. J Ind Microbiol Biotechno 33: $55-61$.

23. Schoug A, Olsson J, Carlfors J, Schnürer J, Håkansson S (2006) Freeze-drying of Lactobacillus coryniformis Si3--effects of sucrose concentration, cell density, and freezing rate on cell survival and thermophysical properties. Cryobiology 53: 119-127.

24. Juárez Tomás MS, Bru E, Martos G, Nader-Macías ME (2009) Stability of freeze-dried vaginal Lactobacillus strains in the presence of different lyoprotectors. Can J Microbiol 55: 544-552.

25. Montel Mendoza G, Pasteris SE, Otero MC, Nader-Macías MEF (2014) Surviva and beneficial properties of lactic acid bacteria from raniculture subjected to freeze-drying and storage. J Appl Microbiol 116: 157-166.

26. Otero MC, Espeche MC, Nader-Macías MEF (2007) Optimization of the freezedrying media and survival throughout storage of freeze-dried Lactobacillus gasseri and Lactobacillus delbrueckii subsp. delbrueckii for veterinarian probiotic applications. Process Biochem 42: 1406-1411.

27. Mendoza LM, de Nadra MC, Farías ME (2007) Kinetics and metabolic behavio of a composite culture of Kloeckera apiculata and Saccharomyces cerevisiae wine related strains. Biotechnol Lett 29: 1057-1063.

28. Mendoza LM, Merín MG, Morata VI, Farías ME (2011) Characterization of wines produced by mixed culture of autochthonous yeasts and Oenococcus oeni from the northwest region of Argentina. J Ind Microbiol Biotechnol 38 $1777-1785$.

29. Rudolph AS, Crowe JH (1985) Membrane stabilization during freezing: the role of two natural cryoprotectants, trehalose and proline. Cryobiology 22: 367-377.

30. Leslie SB, Israeli E, Lighthart B, Crowe JH, Crowe LM (1995) Trehalose and sucrose protect both membranes and proteins in intact bacteria during drying. Appl Environ Microbiol 61: 3592-3597.

31. Crowe JH, Carpenter JF, Crowe LM (1998) The role of vitrification in anhydrobiosis. Annu Rev Physiol 60: 73-103.

32. Sun WQ, Davidson $P$ (1998) Protein inactivation in amorphous sucrose and trehalose matrices: effects of phase separation and crystallization. Biochim Biophys Acta 1425: 235-244.

33. Gómez Zavaglia A, Tymczyszyn E, De Antoni G, Aníbal Disalvo E (2003) Action of trehalose on the preservation of Lactobacillus delbrueckii ssp. bulgaricus by heat and osmotic dehydration. J Appl Microbiol 95: 1315-1320.

34. Streeter JG (2003) Effect of trehalose on survival of Bradyrhizobium japonicum during desiccation. J Appl Microbiol 95: 484-491.

35. Font de Valdez G, Savoy de Giori G, Pesce de Ruiz Holgado A, Oliver G (1983) Comparative study of the efficiency of some additives in protecting lactic acid bacteria against freeze-drying. Cryobiology 20: 560-566.
36. Morgan CA, Herman N, White PA, Vesey G (2006) Preservation of microorganisms by drying; a review. J Microbiol Methods 66: 183-193.

37. Zamski E, Schaffer AA (1996) Photoassimilate distribution in plants and crops Source-sink relationships. CRC press, New York, USA

38. Lakshmanan P (2005) Somatic embryogenesis in sugarcane-An addendum to the invited review 'sugarcane biotechnology: The challenges and opportunities. In Vitro Cell Dev Planta Biol 41: 345-363.

39. Benavent JLA (1999) Vinos y bebidas alcohólicas. Servicio de publicaciones Universidad Politécnica de Valencia. Valencia; España, pp: 498.

40. Flanzy C (2003) Enología: Fundamentos científicos y tecnológicos. Ed. AMV Madrid, España.

41. Carvalho AS, Silva J, Ho P, Teixeira P, Malcata FX, et al. (2003) Effect of various growth media upon survival during storage of freeze-dried Enterococcus faecalis and Enterococcus durans. J Appl Microbiol 94: 947-952.

42. Carvalho AS, Silva J, Ho P, Teixeira P, Malcata FX, Gibbs P (2004) Relevant factors for the preparation of freeze-dried lactic acid bacteria. Int Dairy $\mathrm{J} 14$ 835-847.

43. Rathnayaka RMU (2013) Effect of freeze-drying on viability and probiotic properties of a mixture of probiotic bacteria. ARPN J Sci Technol 3: 11.

44. Ciani M, Picciotti G (1995) The growth kinetics and fermentation behaviour of some non-Saccharomyces yeasts associated with wine-making. Biotechnol Lett 17: 1247-1250.

45. Zohre DE, Erten $\mathrm{H}$ (2002) The influence of Kloeckera apiculata and Candida pulcherrima yeasts on wine fermentation. Process Biochem 38: 319-324.

46. Ciani M, Beco L, Comitini F (2006) Fermentation behaviour and metabolic interactions of multistarter wine yeast fermentations. Int J Food Microbiol 108 239-245.

47. Ciani M, Maccarelli F (1998) Oenological properties of non-Saccharomyces yeasts associated with wine-making. World J Microbiol Biotechnol 14: 199-203.

48. Teixeira P, Castro H, Kirby R (1995) Spray drying as a method for preparing concentrated culture of Lactobacillus bulgaricus. J Appl Microbiol 78: 456-462.

49. Gardiner GE, O'Sullivan E, Kelly J, Auty MA, Fitzgerald GF, et al. (2000) Comparative survival rates of human-derived probiotic Lactobacillus paracase and $L$. salivarius strains during heat treatment and spray drying. Appl Environ Microbiol 66: 2605-2612.

50. Nyanga LK, Nout MJ, Smid EJ, Boekhout T, Zwietering MH (2012) Yeasts preservation: alternatives for lyophilisation. World J Microbiol Biotechnol 28 3239-3244.

51. Bolla PA, Serradell Mde L, de Urraza PJ, De Antoni GL (2011) Effect of freezedrying on viability and in vitro probiotic properties of a mixture of lactic acid bacteria and yeasts isolated from kefir. J Dairy Res 78: 15-22. 